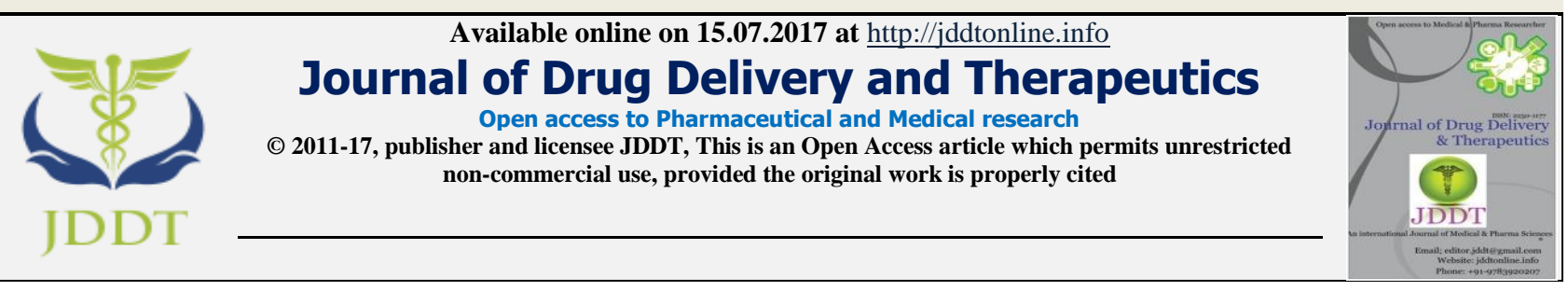

Open $\odot_{\text {Access }}$

Review Article

\title{
PESTICIDES: AN OVEREVIEW
}

\author{
Md. Rageeb Md. Usman*, Koli Deepak Ramdas", Kiran D. Baviskar ${ }^{2}$ \\ ${ }^{* 1}$ Department of Pharmacognosy, Smt. Sharadchandrika Suresh Patil College of Pharmacy, Chopda, Maharashtra, India \\ ${ }^{2}$ Department of Pharmaceutics, Smt. Sharadchandrika Suresh Patil College of Pharmacy, Chopda, Maharashtra, India
}

\begin{abstract}
Majority of the farmers are unaware of pesticide types, level of poisoning, safety precautions and potential hazards on health and environment. According to the latest estimate, the annual import of pesticides in Nepal is about 211 t a.i. with $29.19 \%$ insecticides, $61.38 \%$ fungicides, $7.43 \%$ herbicides and $2 \%$ others. The gross sale value accounts US \$ 3.05 million per year. Average pesticides use in Nepal is $142 \mathrm{~g}$ a.i./ha, which is very low as compared to other Asian counties. Pesticidal miss use is being a serious concern mainly in the commercial pocket areas of agricultural production, where farmers are suffering from environmental pollution. Incidence of poisoning is also increasing because of intentional, incidental and occupational exposure. Toxic and environmentally persistent chemicals are being used as pesticides. Many studies showed that the chemical pollution of the environment has long-term effects on human life. It is therefore essential that manufacture, use, storage, transport and disposal of chemical pesticides be strictly regulated.
\end{abstract}

Key words: Environment, Human-health, Misuse, Pesticides, Pesticide-consumption.

Article Info: Received 14 May, 2017; Review Completed 24 June, 2017; Accepted 24 June, 2017; Available online 15 July, 2017

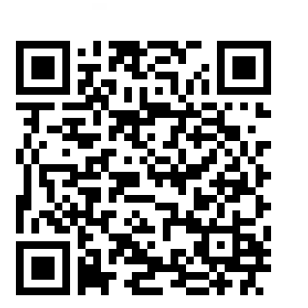

Cite this article as:

Usman MRM, Ramdas KD, Baviskar KD, Pesticides: An Overeview, Journal of Drug Delivery and Therapeutics. 2017; 7(4):1-5

DOI: http://dx.doi.org/10.22270/jddt.v7i4.1462

*Address for Correspondence

Md. Rageeb Md. Usman, M.Pharm., FAPP, FICPHS, MABAP, FSRHCP, FRSH, FSPER

Assistant Professor, Department of Pharmacognosy, Sharadchandrika Suresh Patil College of Pharmacy, Chopda, Maharshtra, India, Email: rageebshaikh@gmail.com

\section{INTRODUCTION ${ }^{1-4}$}

Pesticides were employed to protect crops in classical times using, for example, arsenic compounds and sulphur Smith and Secoy (1975). Since these classical times, pesticides have been used to control harmful organisms to crops, animals and humans (e.g. control of mosquitoes carrying malaria using DDT). Pesticides ensure good crop production and protect animals and humans against pests and diseases Pesticides are chemicals that may be used to kill fungus, bacteria, insects, plant diseases, snails, slugs, or weeds among others. These chemicals can work by ingestion or by touch and death may occur immediately or over a long period of time.

Insecticides are a type of pesticide that is used to specifically target and kill insects. Some insecticides include snail bait, ant killer, and wasp killer. Herbicides are used to kill undesirable plants or "weeds". Some herbicides will kill all the plants they touch, while others are designed to target one species. 


\section{Pesticide Effects on Food Production ${ }^{5}$}

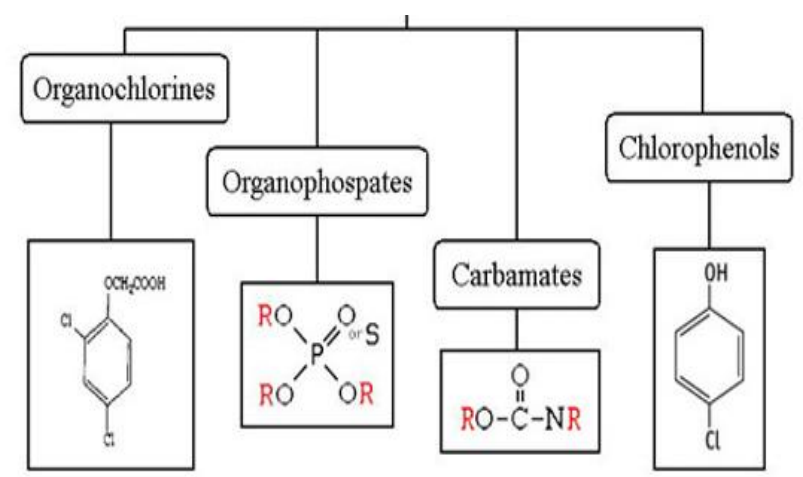

Figure 1: Routes of Exposure: Ingestion, Absorption, Inhalation $^{25}$
As the human population continues to grow, more and more crops are needed to meet this growing demand. This has increased the use of pesticides to increase crop yield per acre. For sample, many farmers will plant a field with Soybeans and apply two doses of Roundup throughout the growing year to remove all other plants and prepare the field for next year's crop. The Roundup is applied twice through the growing season to kill everything except the soybeans, which are modified to be pesticide resistant. After the soybeans are harvested, there is little vegetative cover on the field creating potential erosion issues for the reason that another crop can easily be planted. With this method, hundreds of gallons of chemicals are introduced into the environment every year.

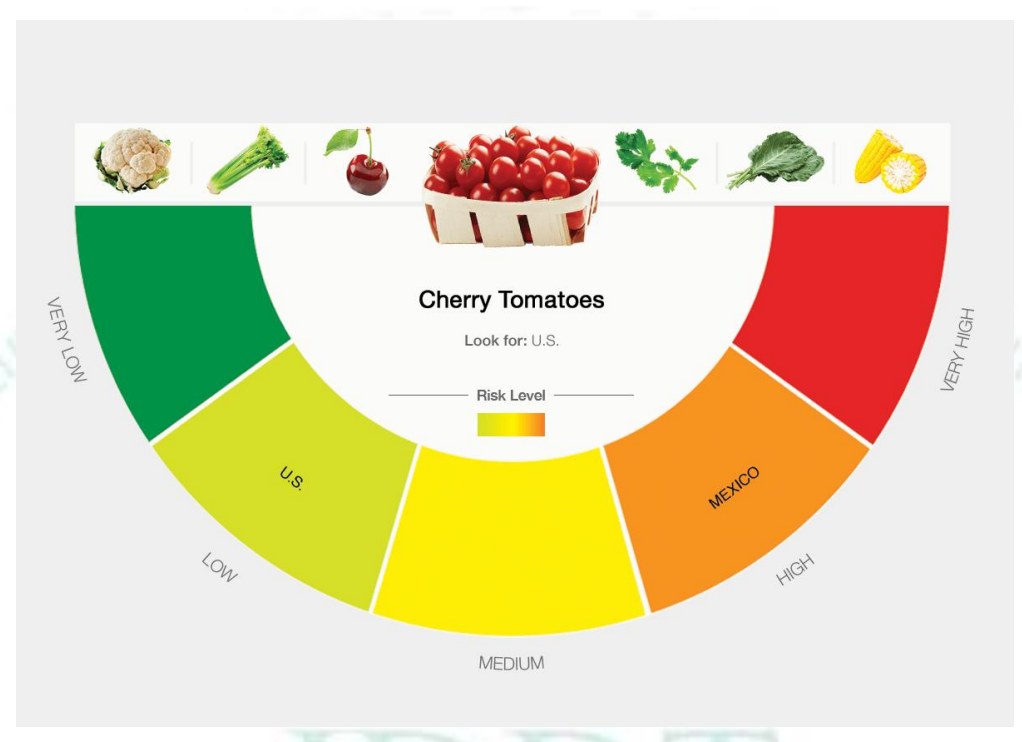

Figure 2: Pesticide Effects

\section{BENEFITS AND RISKS ${ }^{6-7}$}

Pesticides have numerous beneficial effects. These include crop protection, preservation of food and materials and prevention of vector-borne diseases. For example pesticides may be used in the prevention of malaria, which kills up to 1 million children per year, and for preventing other vector-borne diseases such as dengue, leishmaniasis and Japanese encephalitis. Pesticides are toxic by design - they are BIOCIDES, designed to kill, reduce or repel insects, weeds, rodents, fungi or other organisms that can threaten public health and the economy. Their mode of action is by targeting systems or enzymes in the pests which may be identical or very similar to systems or enzymes in human beings and therefore, they pose risks to human health and environment and most are synthetic. There is growing concern about children's exposure to pesticides and their special susceptibility. Children are not little adults, and may have higher exposures and greater vulnerability at both high and low levels of exposure.

\section{FATE OF PESTICIDES IN PLANT SURFACES CHEMICAL ${ }^{8-15}$}

Although degradation of pesticides is influenced by different environmental processes, Celik et al, (1995) concluded that under natural field conditions volatilization is the main process that affects pesticides. These researchers applied six pesticides (azinphosmethyl, ethion, diazinon, methidathion, phosalone and pirimicarb) to apples and found that volatilization was the dominant process followed by solar irradiation. Bacterial degradation had the lowest influence except for phosalone. Pirimicarb was highly degraded by solar irradiation. Rain wash off can also be very important when it occurs shortly after application. 


\section{Monitoring}

The purpose of pesticide monitoring programs is to ensure that in fruits and vegetables do not exceed maximum residues levels (MRLs) allowed by the government, no misuse of pesticides that could result in unexpected residues in food and that good aricultural practices (GAP) are maintained. Some programmers, mostly in developing countries, are carried out due to the demands by international trade. The results from these monitoring programmers are also used by regulatory bodies for future developments in setting MRLs and risk assessment exercises for public health. In most countries, the monitoring programs are organised by a single agency designated as the competent authority. The agency designs a monitoring plan based on the previous data available from dietary consumption and risk assessment exercises or pesticide usage in the available fruits and vegetables.

\section{Maximum residue level}

Maximum residue levels are the highest levels of residues expected to be in the food when the pesticide is used according to authorised agricultural practices (EFSA 2010). The MRLs are always set far below levels considered to be safe for humans. It should be understood that MRLs are not safety limits, a food residue can have higher level than MRL but can still be safe for consumption. Safety limits are assessed in comparison with acceptable daily intake (ADI) for short term exposure or acute reference dose (ARfD). MRLs are subject to legal requirements in most of the countries. In developed regions like Europe the responsibility of the legislation is lead by the European Commission (EC) with input from the member states, EFSA and the standing committee on the Food Chain and Animal Health. In the US, the leading agency is Environmental Protection Agency (EPA) with input from the United States Department of Agriculture (USDA) and the Scientific Advisory Panel while in New Zealand the leading agency is the New Zealand Food Safety Authority (NZFSA) with input from the Environmental Risk Management Authority. MRL setting can be the responsibility of one or more authorities in a country and normally involves the health, agriculture and environmental agencies. MRL enforcement can be a responsibility of one or more agencies and may also depend on different food types. MRL setting is based on the national registered good agriculture practice (GAP) data combined with the estimated likely residue from the supervised trials mean residue (STMR) Children are exposed in different settings and by a variety of routes.

-Pesticides may be unsafely used in the home, by parents who want to protect their children From mosquitoes, cockroaches or rodents. Different pesticides may be stored within the Reach of children. They are used in schools and playgrounds (in treated wood) and in green Areas (parks and playing fields) to destroy weeds. Hospitals are intended to be places of Healing, yet many are using hazardous pesticides
-Living on farms or in agricultural areas, where pesticides are frequently and heavily used, is A high-risk scenario for exposure.

-Potential for "take home" of pesticides on parents' clothing or shoes.

-Pesticides may be present in food and water, either as residues from treatment of crops or

At higher levels, as a result of contamination.

-In some areas, there is a potential for release into the environment during production and Formulation of pesticides (in factories).

-These are the circumstances under which children may receive acute and high-level exposure leading to poisoning or chronic, low-level exposures linked to more subtle, developmental and other effects. (See next slide)

\section{* Pesticides in: homes and schools, playgrounds, parks fields, hospitals and other public places \\ * Children in: work places, farms, agricultural areas (rural setting) \\ * Pesticides present in: air, soil, food, water, parents' clothing and shoes, other objects... \\ Different scenarios:

$\begin{array}{ll}* \text { ACUTE } & \text { high-level exposure, overt poisoning } \\ * \text { CHRONIC } & \text { low-level, chronic exposure, various effects }\end{array}$

Figure 3: Chldrens Environmental Exposure

\section{TYPES OF PESTICIDES ${ }^{16-18}$}

Pesticides come in many forms:

Bactericides-for the control of bacteria

Fungicides-for the control of fungi \& oomycetes

Herbicides for the control of weeds Insecticides for the control of insects - these can be

Voices- (for eggs),

Larvicides-(for larva or baby insects) or Adulticides(for mature insects)

Matricides- for the control of mites Molluscicidesfor the control of slugs and snails

Nematicides- for the control of nematodes

Rodenticides- for the control of rodents

Virucides- for the control of viruses

All industrialized countries have food monitoring programmers that measure pesticide residues. Levels exceeding the maximum established limits have been reported occasionally in monitored food. Maximum limits for residues have been established only for certain pesticides. Although a single pesticide may be considered safe at a particular level, foods may contain 
residues of several pesticides at the same time (see the next slide for an example of the pesticide application Scheme in apple trees) and to understand the effect of multiple exposures.

\section{Food residues}

\section{\&Many food products have detectable levels of pesticides}

$\star$ Guideline levels of pesticides in food (MRL)

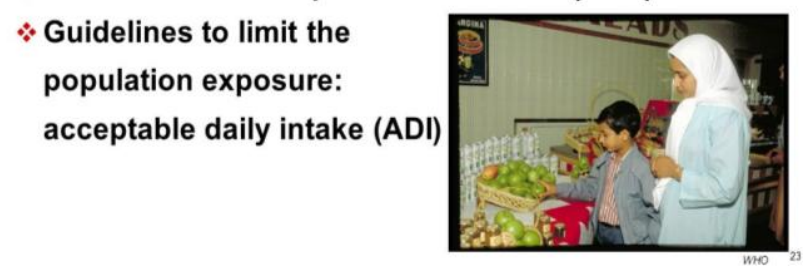

Figure 4: Pesticides in Different Media

Locally grown food may not be properly monitored or controlled for residues of pesticides. Families who eat food directly brought in from fields may have higher pesticide exposure. A study of cumulative dietary pesticide intake in children from an agricultural community showed that Up to $56 \%$ of the children exceeded the acceptable chronic dietary doses (Penske, 2000).

\section{Pesticides can cross the placenta:}

-They have been detected in the amniotic fluid and body tissues of human fetus'seven during early stages of prenatal life.

-Pesticides have also been found in the meconium.

-Residues of organ chlorine pesticides and POPs have been

-There is currently no developed method to measure OPs in breast milk

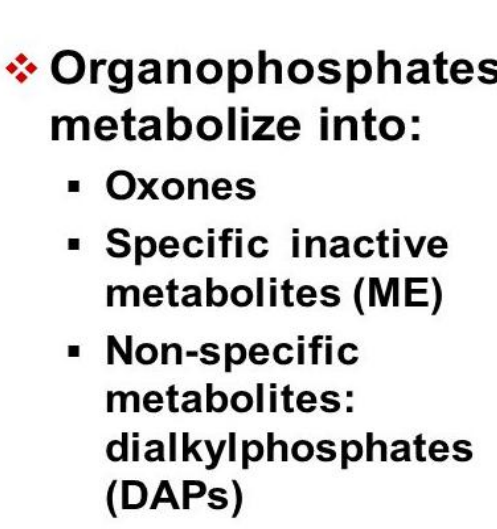

Metabolism may either activate or inactivate the chemical. Therefore, immature metabolic pathways may be protective or increase the danger from Specific chemicals.

As an example, organophosphates are metabolized to ox ones (active metabolite), but also to other specific inactive metabolites (ME) and to non-specific metabolites the Dialkylphosphates (DAPs). DAPs are used as biomarkers of environmental exposure to all kinds of organophosphate Pesticides because DAPs are metabolites of all these pesticides. Several mechanisms of toxicity have been described and these differ according to the Specific properties of the pesticide. They are summarized below.
-Irritation is a local effect due to contact of the pesticide with the skin, eyes or other mucosa. The effects are usually redness and pain.

\section{FUTURE WORK ${ }^{19-22}$}

In pesticide residues research, future work involves mainly the improvement of risk assessment of dietary exposure methods and harmonization of data collection in as many countries as possible. The methods are also aimed at incorporating all the factors that contribute to exposure assessment in the final model predictions so that it can be realistic.

Common methods of dietary exposure assessment were based on deterministic calculations and those have been found to have short comings of only providing exposure for average consumers while excluding higher 
consumers. The most preferred method is the Pesticide Residues in Fruits and Vegetables probabilistic risk assessment since it considers all exposure throughout the entire consumer distribution. In their paper, the authors discuss the risk trade-offs, risk benefits and the use of integrated probabilistic risk assessment model (IPRA). The model integrates exposure and health effect modelling while incorporating variability and uncertainty.

\section{Methods for the determination of pesticide residues $^{23-26}$}

Chromatography (mostly column and gas) is recommended as the principal method for the determination of pesticide residues. These methods may be coupled with mass spectrometry (MS). Samples are extracted by a standard procedure

\section{RESULT}

Injudicious and indiscriminate use of pesticides and presence of pesticide residues in food, fruits, vegetables and environment is a matter of grave-concerns. Banned and highly hazardous pesticides have been used without any precautionary measures. Exposure of farm families to pesticides and intake of pesticides by consumers are a major health threat. Biotic and a biotic systems have been affected entirely. A central authority for chemical safety needs to be formed to work on chemical safety and risk management for coping with pesticide problem

\section{CONCLUSION}

Also the objective of this project is to describe the presence of pesticide residues in fruits and vegetables and how you can evaluate their presence in them to minimize their effects in children's. Pesticides should be used only when the benefits outweigh the risks, and non-chemical pest control procedures have failed. Cosmetic use of pesticides, that is their use to control aesthetically unpleasant plants or no dangerous Insects such as crickets or house millipedes, should be completely avoided.

\section{REFERENCES}

1. American Academy of Pediatrics Committee on Environmental Health. Pesticides. In: Etzel RA editon. Pediatric Environmental health. $2^{\text {nd }}$ editon. Elk Grove Village, American Academy of Pediatrics, 2003, 40-50.

2. Jeyaratnam. Acute pesticide poisoning: a major global health problem. World Health Stat Quarterly, 1990, 145-148.

3. IPCS. The WHO Recommended Classification of pesticides by hazard, Guidelinesto Classification 2000-2002, Tomlin C. The pesticide manual, 11th ed. British Crop Protection CouncilPublications, 1997, 256-260.

4. IPCS. The WHO recommended classification of pesticides by hazard. Guidelines to Classification 2000-2002.

5. Tomlin C. The pesticide Manual, 12th ed. British Crop Protection Council Publications, 2000, 450-455.

6. Children: a CICH profile, $3^{\text {rd }}$ edition, Canadian Institute of Child Health, 2000, 366-369.

7. Health Canada. Health and the environment: handbook for health professionals. Ottawa, Ministry of Public Work and Government Services, 1998, 545-548.

8. Hodgson. Metabolism. In: Hayes, Handbook of pesticide toxicology. San Diego California, Academic Press Inc. 1991, 158 .

9. Bass JK et al. What is been used at home: a household pesticide survey. Rev Panam Salud Publica, 2001, 9:138.

10. CDC Surveillance for acute insecticide related illness associated with mosquito control efforts Nine States 19992002, 323-325.

11. Fields S. Caution - children at play: How dangerous is CCA? EHP, 2001, 109 A262 (ehp.niehs.nih.gov/docs/2001/1096/focus.html)

12. Forrester MB et al. Epidemiology of lindane exposures for pediculosis reported to poison centers in Texas, 1998-2002. J Toxicol -ClinToxicol, 2004, 42:55, 112-114.

13. Lemus $\mathrm{R}$ et al. Chlorpyrifos: an unwelcome pesticide in our homes. Rev Environ Health, 2000, 15:421, 45-50.

14. WHO. The physical school environment, information series on school health, Document 2. Geneva, World Health Organization.

15. Calvert GM et al. Acute pesticide-related illnesses among working youths, 1988-1999. Am J. Public Health 2003; 93: 605 .
16. Fenske R et al. Biologicallybased pesticide dose estimates for children in an agricultural community. Environ Health Perspect 2000; 108:515.

17. Jensen AF et al. Cumulative Risk assessment of the intake of organo phosphorus and carbamate pesticides in the Danish diet. Food Addit. Contam, 2003; 20:776.

18. Rhorer. Transfer efficiencies of iii pesticides from household flooring surfaces to food. J Exp Anal Environ Epidem 2003; 13:454.

19. Sanborn MD et al. Identifying and managing adverse environmental health effects: 4 Pesticides. CMAJ, 2002; 166:1431.

20. Hodgson. Metabolism. In: Hayes, Handbook of pesticide toxicology. San Diego California, AcademicPress Inc. 1991.

21. Pronczuk $\mathbf{J}$ et al. Global perspectives in breast milk contamination infectious and toxic hazards. Environ Health Perspect, 2002; 110:A349.

22. Whyatt RM et al. Measurement of organophosphate metabolites in postpartum meconiumas a potential biomarker of prenatal exposure. A validation study. Env Health Perspect, 2001; 109:417.

23. Wessels D et al. Use of biomarkers to indicate exposure of children to organophosphate pesticides: implications for a longitudinal study of children's env Health Perspectives, 2003; 111:1939.

24. Sanborn MD et al. Identifying and managing adverse effects: 4 Pesticides. CMAJ, 2002, 166:1431.

25. https://www.google.co.in/search?q=Pesticides\&source=lnms $\& \mathrm{tbm}=\mathrm{isch} \& \mathrm{sa}=\mathrm{X} \& \mathrm{ved}=0 \mathrm{ahUKEwiQhdD5uNTUAhULsY} 8$ KHSp6CiwQ_AUICigB\&biw=1366\&bih=662\#tbm=isch\&q =introduction+of+PESTICIDES visited 20/06/2017.

26. Deqing Li, Xin Zhang, Feifan Kong, Food Analytical Methods, Molecularly Imprinted Solid-Phase Extraction Coupled with High-Performance Liquid Chromatography for the Determination of Trace Trichlorfon and Monocrotophos Residues in Fruits, May 2017; 10(5):12841292 . 